\title{
Metodologia para Avaliação de Rotas Cicloviárias sob o Enfoque da Psicologia Ambiental
}

\author{
Methodology for Evaluation of Cycle Routes Under the \\ Environmental Psychology Approach
}

Metodología para Evaluación de rutas ciclistas bajo Enfoque de la Psicología Ambiental

Recebido em 03/12/2020 Aceito em 02/07/2021

\author{
Cristiano Farias Almeida ${ }^{1}$ \\ Luciana Joyce Hamer ${ }^{2}$ \\ Mario Cools ${ }^{3}$
}

1 Universidade Federal de Goiás; Faculdade de Artes Visuais; Programa de Pós-Graduação em projeto e Cidade. Goiânia, Goiás, Brasil. cristianofarias@ufg.br ORCID: 0000-0002-5769-3675

2 Universidade Federal de Goiás; Faculdade de Artes Visuais; Programa de Pós-Graduação em projeto e Cidade. Goiânia, Goiás, Brasil. lucianaj.hamer@gmail.com ORCID: 0000-0002-8911-9811

3 Universidade de Liège; Centro de Transporte, Mobilidade e Logística; Departamento de Engenharia Urbana e Ambiental. Liège, Valônia, Bélgica. mario.cools@uliege.be ORCID: 0000-0003-3098-2693 


\title{
Resumo
}

Este estudo teve como objetivo desenvolver uma metodologia para avaliação de rotas cicloviárias por meio de indicadores e baseada na Psicologia Ambiental e nas características físicas do espaço urbano. Para o estudo do comportamento do indivíduo no meio urbano foram adotados os parâmetros de legibilidade e apreensão do "lugar", além dos fundamentos apresentados pela Psicologia Ambiental: espaço pessoal, territorialidade, privacidade e densidade/apinhamento em sua relação com o ciclismo. As variáveis apresentadas foram mensuradas por meio da Análise Hierárquica, na qual o objetivo foi avaliar o Índice de Condição de Via, que possibilitou a definição de um segmento mais eficiente de uma rede viária1 para compor o sistema cicloviário. A metodologia é composta pelas seguintes etapas: delimitação da área de estudo, caracterização da área de estudo, identificação dos segmentos com maior potencial para viagens com bicicletas, avaliação do índice de condição do percurso, análise das oportunidades de intervenção e escolha do trecho de implantação. Como validação do método apresentado foi feito um estudo de caso na cidade de Goiânia. Assim, pretende-se auxiliar gestores e profissionais na tomada de decisão quanto implantação de rotas cicloviárias dentro de uma perspectiva comportamental.

Palavras-Chave: Ciclovias, mobilidade urbana, psicologia ambiental.

\begin{abstract}
This study aimed to develop a methodology for evaluation of cycle routes through indicators and based on Environmental Psychology and the physical characteristics of the urban space. For the study of the people behavior in the urban environment, the legibility and apprehension parameters of the "place" were adopted in addition to the foundations presented by Environmental Psychology: personal space, territoriality, privacy and density/crowding in its relation with cycling. The variables presented were measured through the Hierarchical Analysis in order to evaluate the Via Condition Index, which enabled the definition of a more efficient segment in a road network 1 to compose the cycling system. The methodology is composed of the following steps: area delimitation, characterization of the area of study, identification of the segments with greater potential for trips with bicycles, evaluation of the condition index of the route, analysis of intervention opportunities and choice of the stretch of implementation. $A$ case study was carried out in the city of Goiannia in order to validate the presented methodology. Thus, it is intended to assist managers and professionals in decision making regarding the implementation of cycle routes within a behavioral perspective.
\end{abstract}

Key-Words: Cycle routes, urban mobility, environmental psychology.

\section{Resumen}

Este estudio tuvo como objetivo desarrollar una metodología de evaluación de rutas ciclistas através de indicadores, basada en la Psicología Ambiental y en las características físicas del espacio urbano. Para el estudio del comportamiento del individuo en el medio urbano de adoptaron los parámetros de legibilidad y aprehensión del "lugar", además de los fundamentos presentados por la Psicología Ambiental: espacio personal, territorialidad, privacidad y densidad / hacinamiento en su relación con le ciclismo. Las variables presentadas se midieron mediante Análisis Jerárquico, en el cual el objetivo fue evaluar el Índice de Condición Vial, lo que permitió definir un tramo más eficiente de una red vial1 para componer el sistema ciclista. La metodología consta de los siguientes pasos: delimitación del área de estudio, caracterización del área de estudio, identificación de los tramos con mayor potencial de intervención y elección del tramo de despliegue. Como validación del método presentado, se realizó un estudio de caso en la ciudad de Goiânia. De esta forma, se pretende ayudar a los gestores y profesionales en la toma de decisiones sobre la implementación de rutas ciclistas desde una perspectiva conductual.

Palabras clave: carriles bici, movilidad urbana, psicología ambiental. 


\section{Introdução}

Os problemas de mobilidade urbana no Brasil atingem pontos alarmantes, e assiste-se a propostas políticas de intervenção em que o automóvel prevalece sobre os demais modos de deslocamentos, e com isso avançam os problemas que vão além da implantação de sua infraestrutura, como problemas ambientais e de saúde pública, decorrentes da má qualidade do ar; elevado número de acidentes de trânsito; congestionamentos ocasionados pela baixa capacidade viária; elevado índice de ocupação na área urbana; falta de estacionamentos; alto consumo de energia, poluição sonora; segregação social, falta de acessibilidade e estresse.

Nesse contexto, a bicicleta se apresenta como uma alternativa de mobilidade em que pode-se identificar vários benefícios, entre eles destacam-se: a preservação dos espaços públicos, menores áreas de estacionamento em relação ao automóvel, baixo nível de ruído, não utilização de combustível fóssil, além de ser economicamente acessível a uma grande parcela da população (FHWA,1999). Apesar de todas as características positivas relacionadas ao uso da bicicleta, as infraestruturas cicloviárias avançam de forma tímida, a falta de investimento e a escassez de diretrizes que incluam a bicicleta como uma alternativa viável para nortear as políticas de estímulo aos modos não motorizados são as principais razões deste quadro (KIRNER, 2006).

Portanto, a inclusão da bicicleta nos deslocamentos urbanos deve ser abordada como elemento integrante do sistema viário, a fim de proporcionar inclusão social, redução de poluentes e melhoria da saúde da população. Os planejadores estão se deparando com contínuo crescimento do uso deste meio de transporte, tanto nas viagens regulares (trabalho e/ou escola) como para a saúde e recreação.

Entretanto, ainda pode ser considerado insuficiente o conhecimento, principalmente no Brasil, sobre o comportamento do usuário de bicicleta, como foi o exemplo do estudo feito por Davis e Wicklatz (2001), os quais identificaram que as rotas usadas pelos ciclistas não passavam pelas ciclovias e ciclofaixas construídas, e um dos principais motivos apontados seria sua infraestrutura construída adjacente às vias de fluxo motorizado que estavam regularmente congestionadas.

Estabelecer critérios e parâmetros eficientes que promovam melhores condições para a implantação das ciclovias vem sendo o grande desafio. Critérios e parâmetros estes que transcendem aos elementos técnicos, em que os aspectos socioeconômicos, culturais e comportamentais também influenciam na escolha deste modelo de deslocamento e na das vias a serem implantadas.

Neste contexto, a Psicologia Ambiental se destacar como uma ferramenta que pode auxiliar na identificação de aspectos comportamentais que representem a apropriação da infraestrutura pelo ciclista, os quais podem ser usados na definição de rotas cicloviárias, pois segundo Hobsbawn (2002), ao andar de bicicleta, a relação do indivíduo com a cidade e seus habitantes conota cumplicidade.

Logo, este estudo teve como objetivo desenvolver uma metodologia para avaliação de rotas cicloviárias por meio de indicadores e baseada na Psicologia Ambiental e nas características físicas do espaço urbano. Nesse sentido, o presente trabalho pode contribuir para a tomada de decisão de gestores e técnicos quanto a implantação de rotas cicloviárias. Sabe-se que este processo faz parte de um planejamento urbano de grande escala, o qual envolve as políticas públicas e a sociedade.

\section{Nível de Serviço como Critério de Avaliação de Rotas Cicloviárias}

Diversas metodologias chamadas como Níveis de Serviços (NS) foram desenvolvidas para avaliar a qualidade do sistema cicloviário em regiões urbanas centradas na infraestrutura (ver Hamer, 2017). Tais metodologias iniciam pela análise qualitativa considerando o conforto, a conveniência do condutor do veículo, a liberdade na escolha da velocidade e os obstáculos que surgem durante o trajeto (TRB, 2000). Alguns métodos criados expõem índices relacionados à convergência de vias e aspectos co- 
nectados ao comportamento espacial (Hamer, 2017). No Quadro 1, desenvolvido por Monteiro e Campos (2011), apresenta-se resumo dos métodos de análise.

Quadro 1: Métodos de análises de ciclistas.

\begin{tabular}{|c|c|c|}
\hline $\begin{array}{l}\text { Autores/ } \\
\text { ano }\end{array}$ & Estudo & Variáveis de Segurança cicloviária \\
\hline $\begin{array}{l}\text { Epperson } \\
\text { e Davis } \\
\text { (1994) }\end{array}$ & $\begin{array}{l}\text { Avaliação do nível de serviço através } \\
\text { de um método que determina o } \\
\text { cálculo do Índice de Condição da Via } \\
\text { (ICV). }\end{array}$ & $\begin{array}{c}\text { Limite de velocidade } \\
\text { Largura da faixa externa } \\
\text { Volume de tráfego médio diário } \\
\text { Quantidade de faixas de tráfego } \\
\text { Qualidade do pavimento } \\
\end{array}$ \\
\hline $\begin{array}{l}\text { Sorton e } \\
\text { Walsh } \\
\text { (1994) }\end{array}$ & $\begin{array}{l}\text { Avaliação da qualidade das viagens } \\
\text { por bicicletas a partir da relação entre } \\
\text { as características das vias que o } \\
\text { ciclista utiliza e o stress a que este } \\
\text { está sujeito. } \\
\end{array}$ & $\begin{array}{c}\text { Volume de tráfego } \\
\text { Velocidade dos veículos automotores } \\
\text { Largura da Via }\end{array}$ \\
\hline $\begin{array}{l}\text { Botma } \\
(1995)\end{array}$ & $\begin{array}{l}\text { Análise da qualidade das vias para } \\
\text { bicicletas deve ser em relação aos } \\
\text { conflitos entre os próprios ciclistas. }\end{array}$ & Volume de bicicletas \\
\hline $\begin{array}{l}\text { Dixon } \\
(1996)\end{array}$ & $\begin{array}{l}\text { Sistema de pontuação para avaliar } \\
\text { corredores cicloviários. }\end{array}$ & $\begin{array}{c}\text { Conflitos na via } \\
\text { Diferencial de velocidade entre veículos motorizados e } \\
\text { bicicleta } \\
\text { Manutenção das vias }\end{array}$ \\
\hline $\begin{array}{l}\text { Landis et. } \\
\text { al (1997) }\end{array}$ & $\begin{array}{l}\text { Classificação das vias cicláveis, sob o } \\
\text { ponto de vista dos ciclistas. }\end{array}$ & $\begin{array}{c}\text { Volume de tráfego } \\
\text { Número de faixas } \\
\text { Limite de velocidade } \\
\text { Condição do pavimento } \\
\text { Largura média da faixa externa } \\
\end{array}$ \\
\hline $\begin{array}{c}\mathrm{HCM} \\
(2000)\end{array}$ & $\begin{array}{c}\text { Análise da capacidade e o nível de } \\
\text { serviço das instalações para } \\
\text { bicicletas. }\end{array}$ & $\begin{array}{c}\text { Densidade de entradas para veículos } \\
\text { Diferença de velocidade entre bicicletas e automóveis }\end{array}$ \\
\hline $\begin{array}{l}\text { Monteiro e } \\
\text { Campos } \\
(2011)\end{array}$ & $\begin{array}{l}\text { Proposta de indicadores para } \\
\text { avaliação da qualidade dos espaços } \\
\text { para ciclistas. }\end{array}$ & $\begin{array}{c}\text { Travessias seguras por meio de sinalização ou passarelas } \\
\text { Distância segura do fluxo de veículos motorizados } \\
\text { Volume de veículos na via no caso de ciclofaixas } \\
\text { Quantidade de acidentes } \\
\text { Quantidade de entradas para veículos } \\
\text { Velocidade do fluxo dos veículos }\end{array}$ \\
\hline
\end{tabular}

Fonte: Monteiro e Campos (2011).

Os métodos propostos por Dixon (1996) e HCM (2000) são destacados por serem as bases teóricas usadas na construção do índice proposto neste artigo. Dixon (1996) criou uma estrutura de contagem para avaliar o nível de serviço das passagens cicloviárias no município de Gainesville, no estado da Flórida, Estados Unidos. O modelo tinha o propósito de avaliar a alocação dos ciclistas em vias arteriais e coletoras, em áreas urbanas. Tal modelo apoiou-se no princípio de que há um grupo de variáveis que precisa existir em um sistema viário para atrair adeptos do não-transporte.

Na metodologia de Dixon (1996) são considerados seis fatores de análise, a saber: facilidades para bicicletas, conflitos, distância de visibilidade não obstruída, melhorias das interseções para ciclismo, diferencial de velocidade entre veículos e bicicletas, nível de serviço motorizados, manutenção das vias e iniciativas específicas para melhorar o transporte cicloviário (Quadro 2). 
Quadro 2: Sistema de pontuação do Nível de Serviço de segmentos de ciclovias em Gainesville, EUA.

\begin{tabular}{|c|c|c|}
\hline Categoria & Critérios & Pontos \\
\hline \multirow{4}{*}{$\begin{array}{l}\text { Facilidades para bicicletas } \\
\quad(\text { Valor máximo }=10)\end{array}$} & Ciclofaixa - faixa externa $\leq 3,66 \mathrm{~m}$ & 0 \\
\hline & Ciclofaixa - faixa externa $3,67 \mathrm{~m}-4,27 \mathrm{~m}$ & 5 \\
\hline & Ciclofaixa - faixa externa $\geq 4,27 \mathrm{~m}$ & 6 \\
\hline & Ciclovia & 4 \\
\hline \multirow{6}{*}{$\begin{array}{c}\text { Conflitos } \\
(\text { Valor máximo }=4)\end{array}$} & Poucas entradas de garagem e cruzamentos & 1 \\
\hline & Ausência de barreiras & 0,5 \\
\hline & Ausência de estacionamento lateral & 1 \\
\hline & Presença de canteiros centrais & 0,5 \\
\hline & Distância de visibilidade não obstruída & 0,5 \\
\hline & Tratamento de interseções para o ciclismo & 0,5 \\
\hline \multirow{3}{*}{$\begin{array}{c}\text { Diferença de velocidades } \\
\text { entre bicicletas e veículos } \\
\text { motorizados } \\
(\text { Valor máximo }=2)\end{array}$} & $>48 \mathrm{~km} / \mathrm{h}$ & 0 \\
\hline & $33-48 \mathrm{~km} / \mathrm{h}$ & 1 \\
\hline & $24-32 \mathrm{~km} / \mathrm{h}$ & 2 \\
\hline \multirow{3}{*}{$\begin{array}{l}\text { Nível de serviço para } \\
\text { veículos motorizados } \\
(\text { Valor máximo }=2)\end{array}$} & $\mathrm{NS}=\mathrm{E}$ ou $\mathrm{F}$ (ou 6 ou mais faixas de tráfego) & 0 \\
\hline & $\mathrm{NS}=\mathrm{D}$ (e menos de 6 faixas de tráfego $)$ & 1 \\
\hline & $\mathrm{NS}=\mathrm{A}, \mathrm{B}$ ou $\mathrm{C}$ (e menos que 6 faixas de tráfego) & 2 \\
\hline \multirow{3}{*}{$\begin{array}{l}\text { Manutenção das vias } \\
(\text { Valor máximo }=2)\end{array}$} & Problemas graves ou frequentes & -1 \\
\hline & Problemas pequenos e menos frequentes & 0 \\
\hline & Ausência de problemas & 2 \\
\hline \multirow{2}{*}{$\begin{array}{l}\text { Iniciativas voltadas ao } \\
\text { transporte cicloviário } \\
(\text { Valor máximo }=1)\end{array}$} & Sem iniciativas & 0 \\
\hline & Iniciativas existentes & 1 \\
\hline
\end{tabular}

Fonte: Dixon (1996).

Os segmentos são pontuados e classificados entre o Nível de Serviço "A" à "F", sendo: (A) vias seguras e atrativas; (B) adequadas para quaisquer ciclistas; (C) adequadas para maioria dos ciclistas; (D) adequada para ciclistas experientes; $(E)$ requerer cuidados para ciclistas; $(F)$ inadequada.

Hamer (2017) descreve que a metodologia proposta pelo Highway Capacity Manual (TRB, 2000) pode ser usada para avaliar a capacidade e o nível de serviço de facilidades para bicicletas. A autora ainda descrever que o uso de tal metodologia permite identificar os efeitos dos pedestres, da sinalização de trânsito e da interação entre ciclistas no nível de serviço de uma instalação para bicicletas que é medido em termos de eventos ocorridos (encontros e ultrapassagens). O método proposto considera as instalações com fluxo ininterrupto de bicicletas que são vias separadas do tráfego veicular, sem interrupções, além dos pontos terminais, como as facilidades com fluxo interrompido, como por exemplo, ciclofaixas que passam por interseções semaforizadas ou não.

\section{A Psicologia Ambiental e o Transporte}

Para Everett e Watson (1987) é necessário ter entendimento psicológico do transporte como sendo a somatória dos comportamentos individuais; sendo assim, precisa ser considerado sob uma perspectiva humana juntamente com a parte tecnológica (DELABRIDA, 2004) em que busca-se unir o comportamento psicológico dos ciclistas e sua relação com o meio viário, de forma a contribuir na inserção da bicicleta na mobilidade urbana e no planejamento de cidades mais sustentáveis, mais humanizadas e com maior qualidade de vida para sua população.

O conceito de Psicologia Ambiental relacionado ao transporte apresentado por Moser (1998), refere-se ao comportamento do indivíduo mediado por sua percepção, onde considera-se o espaço físico e a percepção dos cenários, o comportamento e experiência humana e a relação recíproca entre ambos.

Para Everett e Watson (1987), o transporte é um fator desafiador para a psicologia ambiental, aplicado ao dia a dia de nossas cidades, e pouco explorado. É necessário ter entendimento psicológico do 
transporte, pois todas as pessoas o usam, e é preciso considerar que o fenômeno transporte é uma somatória dos comportamentos dos indivíduos nos contextos urbanos; sendo assim, precisa ser considerado em uma perspectiva mais humana.

A Psicologia Ambiental estuda "as transações entre indivíduos e seu ambiente físico". Nestas transações, indivíduos modificam o ambiente, e seu comportamento/experiência são modificados pelo "ambiente" (Gifford, 1997). Esse ambiente pode ser composto por vias, veículos, normas sociais, entre outros, como exemplificado por Günther (2003).

É possível compreender como os indivíduos se relacionam com um determinado meio de transporte em um determinado ambiente físico e a dinâmica que se estabelece a partir daí: o impacto que o meio de transporte usado terá sobre a vida das pessoas e como essas pessoas irão modificar esse ambiente e se modificar a partir dessa relação.

A relação de interferências leva em conta três elementos básicos da Psicologia Ambiental: (i) espaço (ou cenário) físico; (ii) comportamento; e (iii) a ligação recíproca entre (i) e (ii). Assim, entende-se que:

a. Espaço físico é a percepção dos cenários físicos, e seus múltiplos sentidos (visão, audição, etc.), mas registra múltiplos estímulos ao mesmo tempo (GUNTHER, 2003);

b. O comportamento e a experiência humana podem ser considerados tanto individualmente quanto em grupo, de forma que o ambiente individual não acontece de maneira isolada, mas na presença, real ou imaginária, de outros, em uma situação que pode ser chamada de ambiente social (GUNTHER, 2003);

c. Relação recíproca consiste nas relações bidirecionais e no impacto das pessoas sobre o espaço e o do espaço sobre as pessoas, mas também no processo de retroalimentação entre o comportamento e experiência das pessoas no espaço físico (GUNTHER, 2003).

\subsection{Variáveis Psicológicas da Mobilidade Urbana}

É possível entender a psicologia como se referindo ao comportamento e à experiência nos atributos do espaço físico, enquanto a noção de ligação recíproca é própria da vertente específica da psicologia ambiental (HEIMSTRA e Mc FARLING, 1978).

Entretanto, os três elementos subsidiam mais áreas de estudo, todas elas potencialmente unidas ou identificáveis pelos elementos: comportamento, espaço e reciprocidade; razão pela qual merecem um rótulo includente da psicologia ambiental no estudo da mobilidade urbana (GUNTHER, 2003).

Para Gunther (2003) "ambiente" engloba as múltiplas formas do espaço físico, além de incluir os objetos que, por suas affordances, afetam a relação pessoa-espaço físico. Tamanho e grau de controle de espaço físico, entretanto, não são apenas um fim em si mesmos, mas também fatores relevantes para o bem-estar da pessoa. O grau de mobilidade afeta o acesso a duas classes de elementos: (a) bens materiais e ideias importantes subjetiva e objetivamente, e (b) affordances do ambiente.

Affordances se refere ao que é oferecido pelo ambiente ao organismo que com ele interage (Gunther, 2003). Vale ressaltar que Lewin (1975) se refere a affordances como sendo o caráter de instigação que determinados objetos ou ambientes possuem de suscitar comportamento de quem os está utilizando, podendo ter caráter prático ou baseado na vivência do seu usuário.

Gunther (2003) agrega a essência do espaço físico ao meio urbano mediante a mobilidade e apresenta quatro conceitos do ambiente físico, salientes para o comportamento e experiência: espaço pessoal, territorialidade, privacidade e densidade/apinhamento (GUNTHER, 2003). 


\subsubsection{Espaço Pessoal}

Conceito proposto por Sommer (1969), o espaço pessoal refere-se a uma área com limites invisíveis que cercam o corpo das pessoas, sendo um território portátil. Reflete dois usos. O primeiro refere-se à zona carregada emocionalmente ao redor de cada pessoa. O segundo uso refere-se aos processos pelos quais as pessoas delimitam e personalizam os espaços que habitam.

Para Lee (1977), toda pessoa tem uma área espacial em torno de seu corpo, cujas fronteiras só existem "na mente" e onde qualquer intrusão por outros é indesejável. Edward Hall (1966), antropólogo, em seu estudo dos modos como o espaço é usado enquanto forma de comunicação, atribui as diferenças culturais os seus limites.

Villaça (2008) complementa afirmando que as dimensões do espaço pessoal estão relacionados com sua história de vida, as condições pessoais do indivíduo nas quais ele se encontra. Já a percepção e o ajustamento à distância interpessoal são muito influenciados pelas tradições e normas culturais, segundo afirmação de Stokols (1996).

Para Gunther (2003) o espaço pessoal é afetado à medida que o movimento no espaço leve o indivíduo ao contato com o espaço pessoal de outro indivíduo. Da mesma maneira, reciprocamente, características de espaço pessoal de um e do outro podem facilitar ou restringir a sua mobilidade.

\subsubsection{Territorialidade}

Gifford (1997) apresenta uma definição abrangente de territorialidade como conjunto de comportamentos e atitudes por parte de um indivíduo ou grupo, baseado em controle percebido, tentado ou real sobre um espaço físico definível, objeto ou ideia, que pode implicar ocupação habitual, defesa, personalização e demarcação.

Os estudos sobre territorialidade foram embasados na perspectiva do comportamento animal, onde territorialidade é tida como um comportamento instintivo do animal para realizar demarcação e para assegurar a defesa de um espaço, garantindo, assim, sua sobrevivência. No entanto, na espécie humana o que se observa é a evidência de um caráter mais social, culturalmente apreendida (HEIMSTRA e Mc FARLING, 1978).

Os estudos sobre territorialidade buscam compreender as relações de domínio e defesa dos diferentes níveis de território, bem como relacionar conceitos de apego e identidade do lugar. A perspectiva social revela como os territórios estão envolvidos por laços afetivos e cognitivos (status, identidade, estabilidade familiar) e servem de suporte para a identidade do possuidor, buscando compreender as relações de apego e identidade do "lugar" (SOMMER, 1969). Além dessas funções sociais, o território ainda tem funções físicas de proteção e controle (PAIVA, 2013).

\subsubsection{Privacidade}

Altman (1975) define privacidade como "controle seletivo do acesso a si mesmo ou a seu grupo" ( $p$. 18), sendo um conjunto aceitável de mecanismos reguladores, fortemente determinados por normas sociais (LEE, 1977). A privacidade desejada varia de acordo com as normas estabelecidas pela sociedade, sua origem, o sexo, a personalidade e o estado de espírito dos indivíduos (LEE, 1977).

A apropriação do espaço e a materialização por meio de elementos construtivos como paredes, janelas, jardins e portas, definem a situação de privacidade, podendo ser controlados, mediante caráter de interesse pessoal (VILLAÇA, 2008).

\subsubsection{Densidade ou Apinhamento}

Densidade diz respeito ao número de indivíduos por unidade de espaço, portanto, uma medida objetiva, enquanto apinhamento refere-se a um estado psicológico que inclui estresse e a motivação de sair de uma situação percebida subjetivamente como densa (BELL et al., 1996). As reações 
individuais aos diferentes níveis de densidade dependem de uma série de fatores. Entre eles destacam-se: características das pessoas e dos grupos, idade, gênero, objetivo das interações, escolha das pessoas de estar naquele ambiente lotado e fatores culturais (MORVAL, 2007).

O conceito de aglomeração "crowding" traduzido para o português como ajuntamento, apinhamento ou superpovoamento, corresponde a uma situação percebida como desconfortável, ocasionado pela invasão de seu espaço pessoal (TUAN, 1983).

\subsection{Aspectos Culturais, Sociais e Econômicos}

O comportamento humano está diretamente ligado ao fator cultural, e com isso, a escolha do meio de transporte se agrega na tomada de decisão do uso do meio de transporte. Tylor (1871) foi um dos precursores da definição de cultura como sendo "todo conhecimento, crença, arte, moral, leis e um sistemas de costumes ou quaisquer outras capacidades ou hábitos adquiridos pelo homem como membro de uma sociedade" (TYLOR, 1871).

Cultura significa todo aquele complexo que inclui o conhecimento, a arte, as crenças, a lei, a moral, os costumes e todos os hábitos e aptidões adquiridos pelo ser humano em família e em uma sociedade da qual é membro. É também um mecanismo cumulativo, porque as modificações trazidas por uma geração passam à geração seguinte, onde vai se transformando, perdendo e incorporando outros aspectos, procurando, assim, melhorar a vivência das novas gerações (BATISTA, 2010).

Para Matos (1999), as regras sociais e sua cultura são sustentadas e se exprimem face a maior exibição de comportamentos de demarcação territorial. Isso implica um comprometimento em pertencer, fortalecendo as verdades em comum de determinado grupo. Após o grande crescimento dos centros urbanos e os incentivos da indústria automobilística ao transporte individual a imagem do automóvel associou-se ao símbolo de poder, prosperidade, sucesso e liberdade (MAOSKI, 2009). Aliado a isso, observa-se que em muitas cidades o desenvolvimento das infraestruturas viárias foi orientado para o uso do automóvel em detrimento aos transportes não-motorizados.

Para Sommer (1969) o ser humano demonstra seus "status" a partir de seu comportamento e do uso de objetos que simbolicamente o indicam e reforçam, reconhecendo sua importância perante um grupo ou sociedade. Delabrida (2004), em seu estudo sobre a imagem da bicicleta, reforça e reafirma que o reflexo de como a bicicleta tem sido utilizada na maioria das cidades ocidentais representa a própria organização social e de seus valores, onde o "carro" simbolicamente representa uma categoria privilegiada, o "status" é dado pelo poder aquisitivo que aquele participante do transito que o expõe. Já quem não o utiliza é visto como um cidadão de "segunda classe" com baixos padrões aquisitivos, pouco privilegiado diante de seu contexto social (PEZZUTO, 2002).

Outro fator que está associado ao "status" social é o nível de escolaridade e a renda dos usuários de bicicletas. Na Holanda e na Dinamarca existe maior tradição no uso da bicicleta como modo de transporte regular. Seu uso é considerado normal e habitual em todas as classes sociais. Quando o ciclismo é integrada à cultura local, outros fatores acabam tendo relevância, como condições físicas, clima, topografia, conforto, atingindo as futuras gerações (PUCHER e BUEHLER, 1999).

De acordo com Rietveld e Daniel (2004), na Holanda 25,6\% das viagens feitas por dia são realizadas por bicicleta, $16 \%$ da malha viária é dedicado ao transporte por bicicleta. Para Sommer (1969) à medida que os usuários de bicicleta ocupam um maior espaço no sistema viário, estacionamentos e demais facilidades são implantadas, trazendo mais conforto, segurança e respeitabilidade ao ciclista.

Vasconcelos (2000) ressalta que recorrer às experiências feitas na Europa para o uso da bicicleta pode trazer boas ideias, mas que se não se considerar que a percepção dos europeus sobre a bicicleta é de aceitação como parte da cidadania, as conclusões podem ser enganadoras e os 
resultados podem ser frustrantes. É preciso levar em consideração essa diferença de percepção. Estudar a imagem pode nos auxiliar a identificar que aspectos dessa percepção são semelhantes e que aspectos são diferentes e nos auxiliar nas intervenções que favoreçam o uso da bicicleta. Para Paiva (2013), os dados anteriormente referendados só reforçam a necessidade de inclusão de aspectos relacionados a territorialidade no instrumento de pesquisa a ser utilizado, caracterizando como os valores culturais também se somam no comportamento espacial dos indivíduos no uso da bicicleta.

\section{Metodologia para Avaliação de Rotas Cicloviárias}

A metodologia a ser apresentada vem como um instrumento que visa auxiliar técnicos no processo de implementação e avaliação dos sistemas cicloviários, e caracteriza-se como um elemento integrante da mobilidade para as cidades e regiões metropolitanas. O método proposto é composta por seis etapas, como segue.

a. Etapa 1 - Delimitação do Área de Estudo: dar-se-á partir da identificação de polos geradores de viagens (PGV) e identificação da área de influência de PGV.

b. Etapa 2 - Caracterização da Área de Estudo: onde será feita coleta de dados da área de estudo a fim de municiar de informações a tomada de decisão quanto à implantação do sistema cicloviário.

C. Etapa 3 - Identificação das Rotas com Potencial à Viagens por Bicicletas: são usados os critérios técnicos referentes aos aspectos espaciais do sistema viário, com foco em identificar as rotas mais usadas, também chamados de "linhas de desejo"

d. Etapa 4 - Avaliação dos Trechos por meio do Índice de Condições da Via (ICV): esta etapa é constituída por três atividades: i) seleção de indicadores para avaliação dos trechos onde propõe-se a implantação do sistema cicloviário; ii) quantificação dos indicadores; iii) definição de ferramenta para avaliação do índice de condição da via.

e. Etapa 5 - Avaliação das Oportunidade de Intervenção: consiste na reavaliação do sistema cicloviário a ser implantado, em que deve-se agregar todas as informações levantadas e estudadas de forma a valorizar os princípios norteadores do sistema cicloviário.

f. Etapa 6 - Seleção das Rotas de Melhor Desempenho: tem como objetivo a classificação e priorização dos trechos com menor necessidade de melhoramentos, servindo como diretriz para a definição das rotas. Logo, propõe-se comparar os trechos avaliados para a escolha da rota de melhor desempenho.

\section{Estudo de Caso}

Para validar a proposta metodológica apresentada, foi realizado um estudo de caso na cidade de Goiânia, Brasil, junto ao Corredor Universitário, compreendido pela Avenida Universitária e rua 261 no Setor Leste Universitário, trecho onde foi implantada a primeira ciclovia dos 14 corredores preferenciais do transporte coletivo na cidade.

A legislação municipal referente ao Plano Diretor de Goiânia traz diretrizes de implantação de ciclovias nos corredores preferenciais de transporte coletivo, assim como o trecho estudado se integra ao Eixo Urbano de Desenvolvimento Econômico que tem como principal objetivo o crescimento da economia e o avanço social da população (GOIÂNIA, 2007). O trecho é integrado às áreas adensáveis da cidade, por ser um corredor preferencial, para as quais são incentivadas as maiores densidades habitacionais e de atividades econômicas, sustentadas pela rede viária e de transporte em uma faixa bilateral contígua em extensão aproximada de 750 m de cada lado da via estruturadora (GOIÂNIA, 2007). 


\subsection{Etapa 1: Definição da Área de Estudo}

A área de estudo definida é o Corredor Universitário, o qual tem como tratamento prioritário o transporte coletivo e modos não-motorizados. A área de estudo abrange os setores Central, Sul e Leste Universitário, composto pela Rua 10, Praça Universitária, Av. Universitária e Rua 261, no Setor Leste Universitário (Figura 1).

Figura 1: Corredor Universitário.

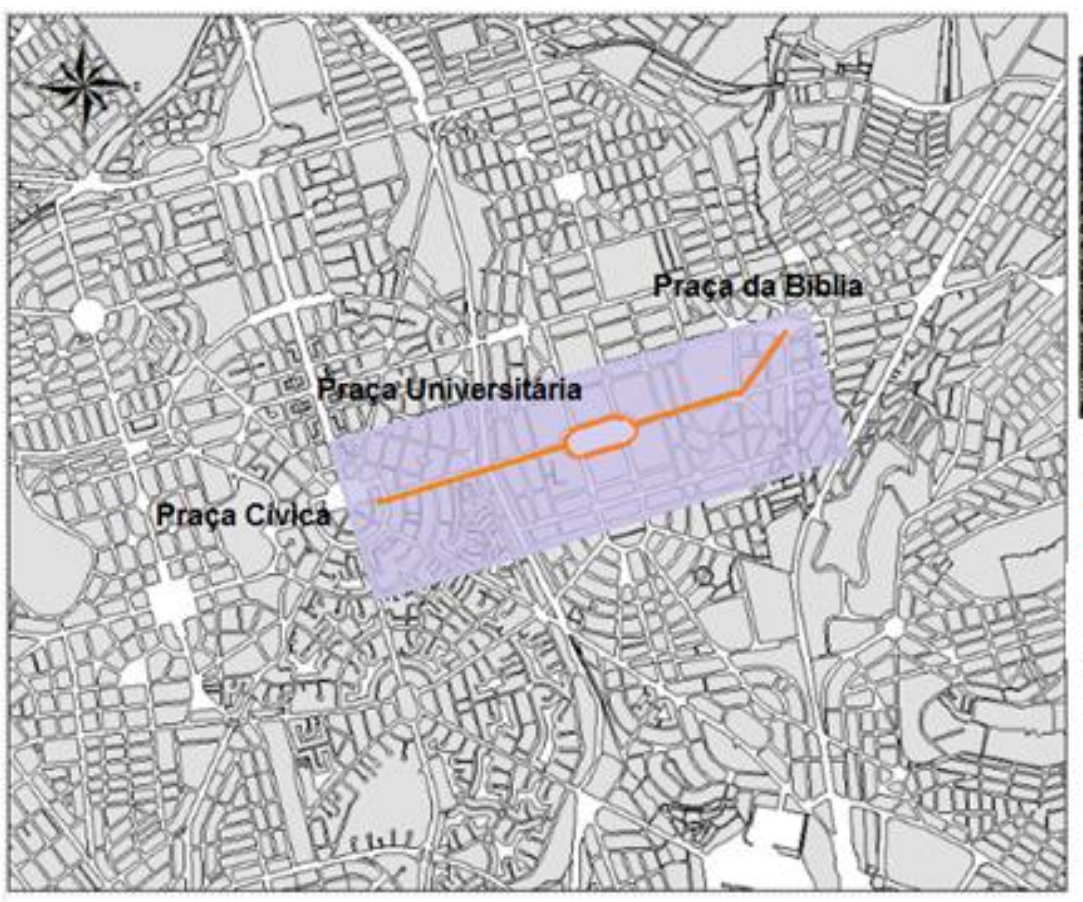

Fonte: MUBDG (2016) adaptada pelo autor
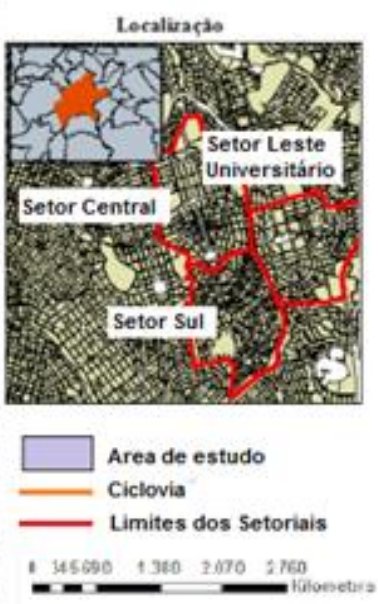

Proiectio Iniver ial fraverso de Mercirtue Duam Sel Aneticano do 196 (SAD d9? Tuse 22 Sol
Meritiano Central $41^{\circ}$ Zona 22

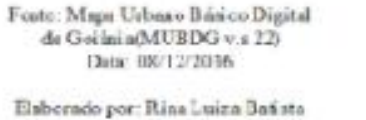

A área escolhida teve como referencial as diretrizes do Plano Diretor quanto à implantação das ciclovias junto aos corredores preferenciais. Tem-se a área de estudo que compreende a Praça Cívica, ponto de convergência das principais linhas da rede de transporte coletivo, até a Praça da Bíblia, onde é localizado o terminal de integração homônimo do transporte coletivo da Região Metropolitana de Goiânia, que merece destaque nessa pesquisa, pois faz parte do cenário delimitado para a região de estudo e por ser considerado de grande potencial de integração da bicicleta. Ambas praças são os PGV que constituem a área de estudo.

Para definição da área de influência, as faixas de tempo de viagens foram convertidas em faixas de distância percorrida (PORTUGAL e GOLDNER, 2003), presumindo que a velocidade média do ciclista em vias urbanas seja de $15 \mathrm{~km} / \mathrm{h}$ (GEIPOT, 2001). A figura 2 exemplifica a representação da área primária do PGV Praça da Bíblia. Assim, há a área primária de 10 minutos (cobrindo raio de 2,5 km), a área secundária de 20 minutos (cobrindo raio de $5 \mathrm{~km}$ ) e a área terciária de 30 minutos (cobrindo raio de $7,5 \mathrm{~km}$ ). 
Figura 2: Área de influência do PGV Praça da Bíblia.

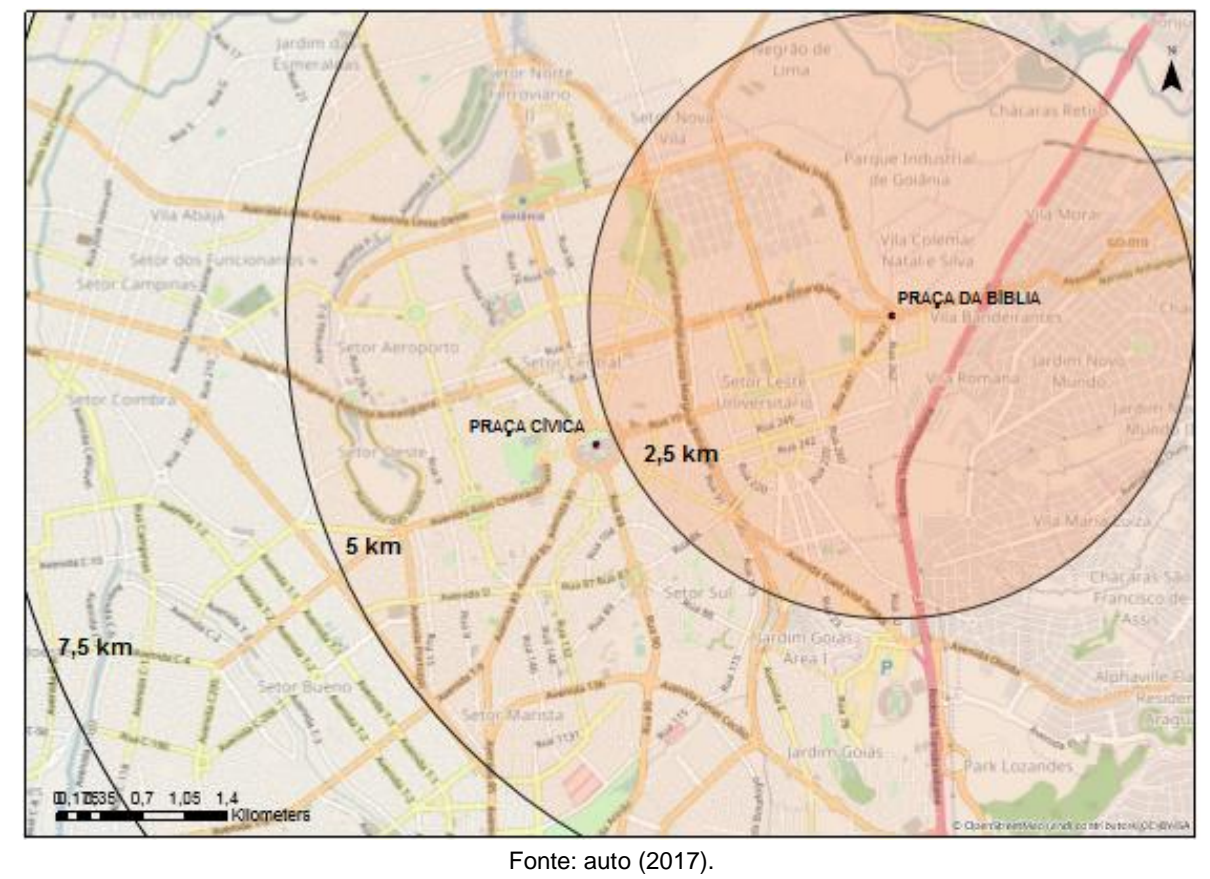

\subsection{Etapa 2: Caracterização da Área de Estudo}

Segundo o IBGE (2010) há em Goiânia um total de 1.302.001 habitantes e a população estimada para 2019 é de 1.516 .113 pessoas. Já o Setor Leste Universitário, região onde o Corredor Universitário tem maior área de ocupação, apresenta estimativa de 21.175 habitantes (SEPLAM, 2010).

Um importante aspecto que caracteriza a região do entorno do Corredor Universitário é a existência constante do público universitário. Pesquisa realizada por Hamer e Almeida (2016a) na Escola de Engenharia Civil e Ambiental da UFG, localizada na Praça Universitária, aponta para um público potencialmente usuário de bicicleta, com faixa etária de 26 anos $(91,7 \%)$, estudantes $(93,3 \%)$. Além disso, o Setor Universitário possui diversos empreendimentos geradores de viagem que surgiram em decorrência da presença da UFG e de outras universidades privadas, o que segundo Kneib (2004), podem causar impactos diversos: em curto prazo, afetando o sistema e a circulação viários; em médio e longo prazos, causando impactos na estrutura urbana, como por exemplo, valorização do solo urbano.

Moysés (2008) aponta que o Setor Universitário apresenta forte potencial construtivo em função da demanda de moradia e comércio. A região é economicamente ativa, conforme dados apresentados pela SEPLAM (2010) onde têm-se: atividades de serviços, comércio, indústria, setor primário e outros, totalizando 3.524 registros, face ao total de 188.464 registros de atividades de todo o município.

No corredor Universitário não é diferente. Um vasto comércio se estende por grande parte do perímetro da avenida, além das instituições de ensino, equipamentos de saúde (clínicas e hospitais), edificações unifamiliares, edificações coletivas e instituições de uso público e coletivo, conforme apresentado na Figura 3. Tais características demonstram potencial uso de bicicletas para atender as necessidades diárias de quem visita constantemente a área. 
Figura 3: Tipo de uso do solo da avenida Universitária.

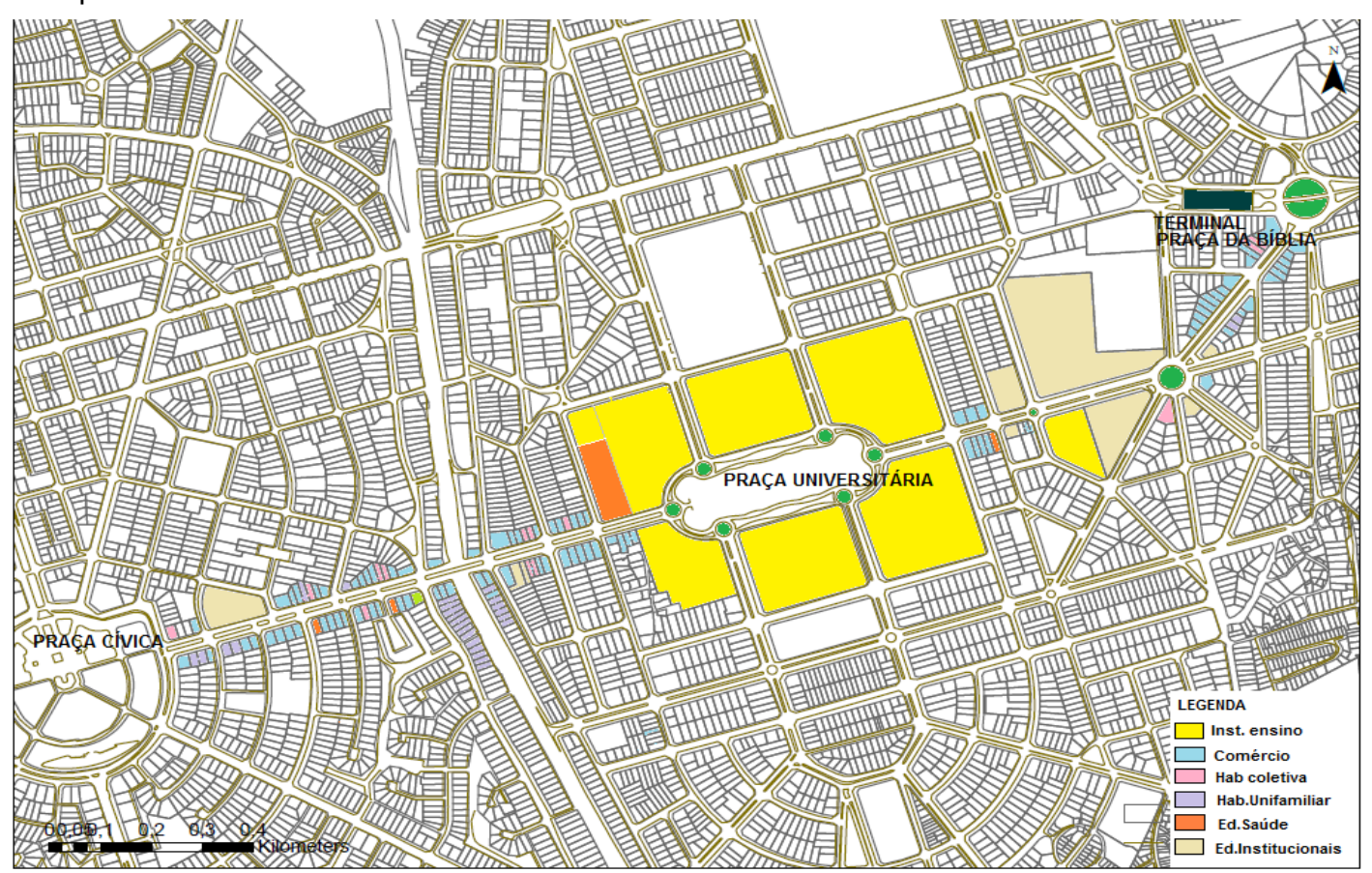

Fonte: Autor (2017).

\subsection{Etapa 3: Identificação das Rotas com Potencial à Viagens com Bicicletas}

Como a estrutura cicloviária deve ser implantada em vias já existentes com características de tráfego já estabelecidas, é necessário analisar o sistema viário como está implantado, buscando percursos já consolidados. Assim, buscou-se traçar possíveis rotas que garantam a conectividade do usuário de bicicleta e a fluidez do tráfego.

Após definidos os principais pontos de atração de viagens, são selecionadas as vias de menor percurso possível, as quais constituem rotas capazes de atender às solicitações de continuidade, direção e destino de serviço. Assim, as rotas foram identificadas com o auxílio do Sistema de Informação Geográficas de Goiânia (SIG). Logo, tem-se as seguintes rotas (ver Figura 4):

a. ROTA 1 (linhas em vermelho): trecho com 2,8 $\mathrm{km}$ de percurso, tempo estimado para bicicletas de aproximadamente 12 minutos. Refere-se a "rota estudada", atende à demanda quanto ao fluxo cicloviário dentro de uma proposta de caminho mínimo, coincidente com o eixo viário estruturante e corredor, rota direta e com intersecções sinalizadas.

b. ROTA 2 (linhas em laranja): trecho com 3,1 km de percurso, tempo estimado para bicicletas de 16 minutos, opção apresentada busca atingir um número maior de pontos de atividade por meio de itinerário mais abrangente.

C. ROTA 3 (linhas em amarelo): buscou-se definir uma rota que tivesse maior abrangência de atividades socioeconômicas localizadas ao norte da rota, mas a proposta não se mostrou favorável quanto a linearidade do percurso, sofrendo um aumento de percurso superior a $15 \%$ do trecho principal (proposta recusada). 
Figura 4: Rotas possíveis entre os PGV.

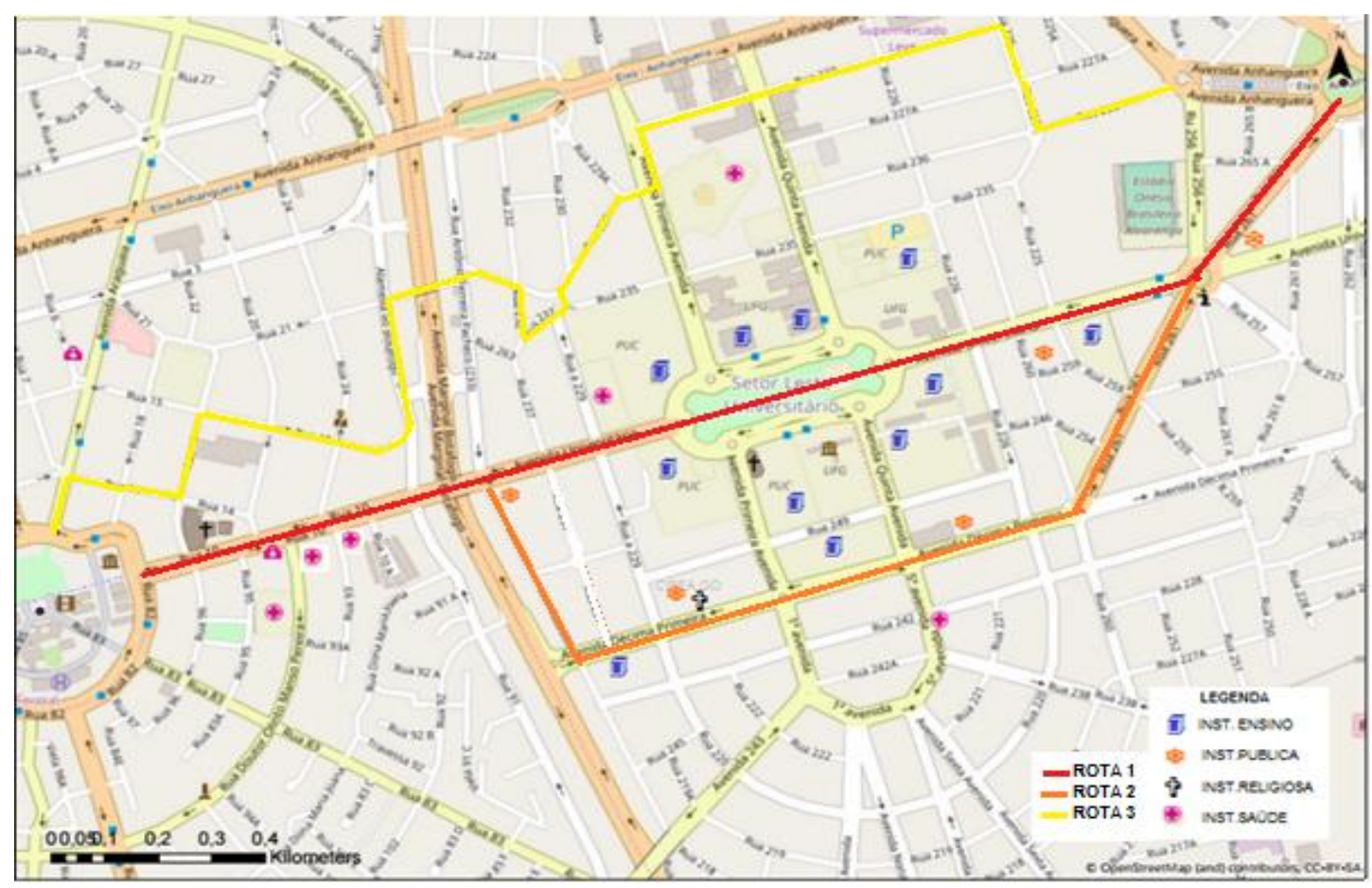

Fonte: Autor (2017).

Para Segadilha (2014) uma diferença aceitável para mudança de rota de um ciclista pode chegar até $15 \%$ do valor total de seu percurso. A diferença em termos de extensão entre as rotas analisadas (Rota 1 e Rota 2) apresentou valor de $10 \%$ de acréscimo ao total da rota. Para a avaliação do Índice de Condição da Via (ICV) é necessário que as rotas sejam divididas em trechos homogêneos conforme suas características físicas (largura, topografia e velocidade da via). Dessa forma, foi proposta tal divisão conforme apresentada na Figura 5, detalhada no quadro 3.

Figura 5: Divisão das rotas em trechos.

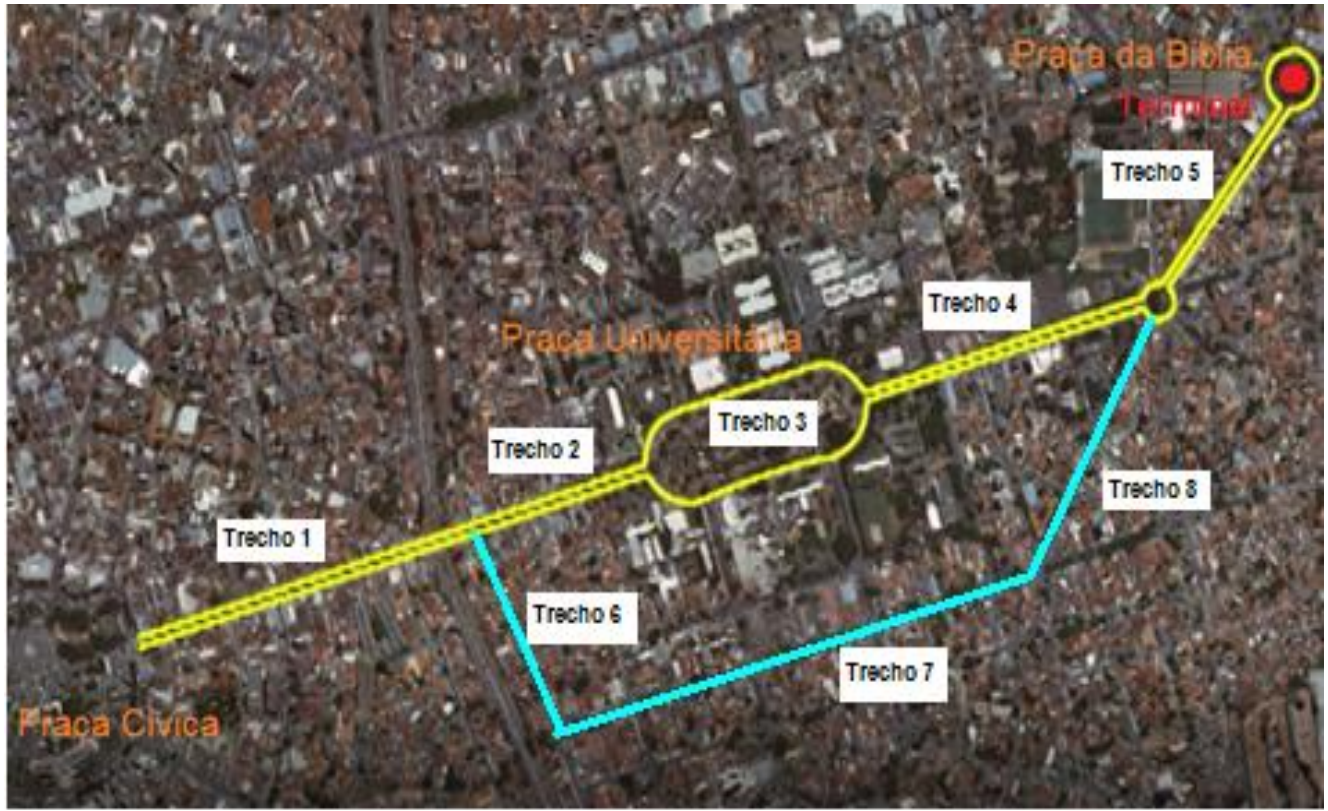

Fonte: Autor (2017). 
Quadro 3: Descrição dos trechos das duas rotas analisadas.

\section{ROTA 1 com 2.800 m de extensão}

Trecho 1: Avenida Universitária (Praça Cívica até a Alameda do Botafogo) comprimento de $600 \mathrm{~m}$

Trecho 2: Avenida Universitária (Alameda do Botafogo até a Praça Universitária) comprimento de $450 \mathrm{~m}$

Trecho 3: Praça Universitária (caminhos internos), comprimento de $600 \mathrm{~m}$

Trecho 4: Avenida Universitária (Praça Universitária até a Praça Tem. Veríssimo de Souza e Silva) comprimento $450 \mathrm{~m}$

Trecho 5: Rua 261 (Praça Tem. Veríssimo até Praça Bíblia) comprimento de $700 \mathrm{~m}$

\section{ROTA 2 com 3.100 m de extensão}

Trecho 1: Praça Cívica até a Alameda do Botafogo - comprimento de $600 \mathrm{~m}$

Trecho 6: Rua 233 (Avenida Universitária até 11aㅡ Avenida) - comprimento de $350 \mathrm{~m}$

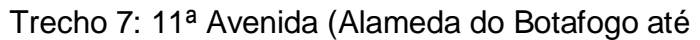
rotula da R.261) - comprimento de $1000 \mathrm{~m}$

Trecho 8: Rua 261 (11를 Avenida até a Praça Tem. Veríssimo) - comprimento $450 \mathrm{~m}$

Trecho 5: Rua 261 (Praça Tem. Veríssimo até Praça Bíblia) - comprimento de $700 \mathrm{~m}$

Fonte: Autor (2017).

Após escolher as rotas a serem trabalhadas, é preciso analisar a morfologia urbana de cada trecho, de forma a evidenciar os elementos com potencialidades de atratividade para o uso da bicicleta (KIRNER, 2006). O quadro 4 apresenta a morfologia urbana dos trechos.

Quadro 4: Descrição da morfologia urbana dos trechos que constituem as rotas analisadas.

\begin{tabular}{ll}
\hline Trecho & Descrição \\
\hline Trecho 1 & $\begin{array}{l}\text { Praça Cívica até a Alameda Botafogo: via arterial, em declive, com presença de canteiro } \\
\text { nas laterais da via em bom estado de conservação e faixas de pedestres sinalizadas. Área } \\
\text { namercial desenvolvida, com presença de poucos edifícios multifamiliares. }\end{array}$
\end{tabular}

Trecho 2

Av. Universitária (Alameda do Botafogo até a Praça Universitária), comprimento de 450m: via arterial em aclive e com canteiro central. Vegetação presente. Comércio desenvolvido com presença de vários edifícios comerciais voltados ao serviços de atendimento às universidades e usuários do hospital, tais como: lanchonetes, farmácia, papelaria, outros.

Praça Universitária (caminhos internos), comprimento de 600m: área em aclive bastante

Trecho 3 arborizada e com circulação constante de pedestres. Em seu perímetro encontram-se a Universidades Federal de Goiás e a Pontifícia Universidade Católica, no local situam-se: bares, lanchonete e biblioteca.

Av. Universitária (Praça Universitária até a Praça Tem. Veríssimo de Souza e Silva), comprimento $450 \mathrm{~m}$ : avenida apresenta topografia plana e a vegetação existente no local

Trecho 4 com pouco sombreamento. A maioria das edificações existentes ao longo do percurso são de até 3 pavimentos, presença de clube recreativo, universidades, escola profissionalizante.

Rua 261 (Praça Tem. Veríssimo até Praça Bíblia), comprimento de 700m: topografia plana, Trecho 5 presença de vegetação com sombreamento. A maioria das edificações existentes ao longo do percurso são de até 3 pavimentos e com baixa circulação de pedestres no local.

Trecho 6

Rua 233 da Av. Universitária até 11a Av., comprimento de $350 \mathrm{~m}$ : via coletora, trecho plano, mão única, não existe circulação de transporte coletivo, comércio pouco desenvolvido.

Trecho 7 11 Av. (Alameda do Botafogo até a rótula da R.261), comprimento de 1,000m: trecho em ções públicas e residências unifamiliares, comércio pouco desenvolvido. 
Rua 261 (11 a Avenida até a Praça Tem. Veríssimo), comprimento 450m: trecho com Trecho 8 declividade moderada, canteiro central com presença de vegetação, edificação na sua maioria com até 3 pavimentos, presença de habitações unifamiliares, comércio pouco desenvolvido. Presença de edifícios que trás pouca atratividade ao local.

Fonte: Autor (2017).

\subsection{Etapa 4: Avaliação dos Trechos por meio do Índice de Condição da Via (ICV)}

Esta etapa foi elaborada com base nos níveis de serviços apresentados no item 2 deste trabalho. Tais níveis de serviços foram usados, também, por Hamer e Almeida (2016b) para desenvolver oito indicadores que compõem o Índice de Condição da Via (ICV), sendo eles: largura da via, velocidade, topografia, conflitos (estacionamentos, cruzamentos sem sinalização), fluxo de veículos, amenidades, pavimentação (qualidade) e uso do solo. Aplicou-se, então, o Método de Análise Hierárquica (MAH) desenvolvido por Saaty (1991) para se obter a hierarquização e mensuração dos oito indicadores.

Foram entrevistados quatro profissionais especialistas da área técnica em transportes e seis ciclistas usuários de bicicleta para seu deslocamento pendular, em que este último grupo se subdividiu em dois: ciclistas com mais de três anos de experiência e ciclistas com menos de três anos de experiência no uso da bicicleta para viagens pendulares. Obteve-se a média aritmética dos indicadores ao aplicar os questionários junto aos entrevistados (tabela 1).

Tabela 1: Médias aritméticas dos indicadores aplicados junto aos entrevistados.

\begin{tabular}{llllllllll}
\hline & $\begin{array}{l}\text { Largura } \\
\text { da Via }\end{array}$ & $\begin{array}{l}\text { Velo- } \\
\text { cidade }\end{array}$ & $\begin{array}{l}\text { Topo- } \\
\text { grafia }\end{array}$ & $\begin{array}{l}\text { Con- } \\
\text { flitos }\end{array}$ & $\begin{array}{l}\text { Fl. de } \\
\text { Veículos }\end{array}$ & $\begin{array}{c}\text { Ameni- } \\
\text { dades }\end{array}$ & $\begin{array}{l}\text { Pavi- } \\
\text { mento }\end{array}$ & $\begin{array}{l}\text { Uso } \\
\text { do solo }\end{array}$ & IC \\
\hline Resp 1 & 0,18 & 0,22 & 0,17 & 0,13 & 0,13 & 0,07 & 0,07 & 0,04 & 0,04 \\
Resp 2 & 0,30 & 0,25 & 0,16 & 0,06 & 0,07 & 0,06 & 0,06 & 0,06 & 0,07 \\
Resp 3 & 0,27 & 0,19 & 0,15 & 0,11 & 0,12 & 0,06 & 0,07 & 0,03 & 0,03 \\
Resp 4 & 0,18 & 0,22 & 0,17 & 0,13 & 0,13 & 0,07 & 0,07 & 0,04 & 0,04 \\
Resp 5 & 0,25 & 0,25 & 0,14 & 0,10 & 0,12 & 0,08 & 0,03 & 0,04 & 0,02 \\
Resp 6 & 0,30 & 0,13 & 0,16 & 0,07 & 0,11 & 0,04 & 0,06 & 0,05 & 0,06 \\
Resp 7 & 0,27 & 0,25 & 0,20 & 0,05 & 0,06 & 0,06 & 0,06 & 0,05 & 0,08 \\
Resp 8 & 0,28 & 0,25 & 0,07 & 0,08 & 0,17 & 0,07 & 0,04 & 0,02 & 0,02 \\
Resp 9 & 0,28 & 0,25 & 0,14 & 0,10 & 0,08 & 0,07 & 0,06 & 0,02 & 0,02 \\
Resp 10 & 0,28 & 0,23 & 0,08 & 0,09 & 0,18 & 0,07 & 0,05 & 0,02 & 0,02 \\
Media & 0,259 & 0,224 & 0,144 & 0,092 & 0,117 & 0,065 & 0,057 & 0,037 & -17 \\
\hline
\end{tabular}

Fonte: Autor (2017).

A figura 6 apresenta o percentual avaliativos dos indicadores para a elaboração do Índice de Condição da Via, conforme médias apresentadas no Método de Análise Hierárquica (MAH).

Definidos os indicadores para a avaliação do Índice de Condição da Via, obteve-se a tabela 2 com os pesos a serem aplicados nos trechos viários que constituem as duas rotas estudadas. Cada trecho analisado receberá uma nota que poderá chegar até 1,0 ponto. 
Figura 6: Percentual avaliativos para os indicadores analisados pelo $\mathrm{MAH}$.

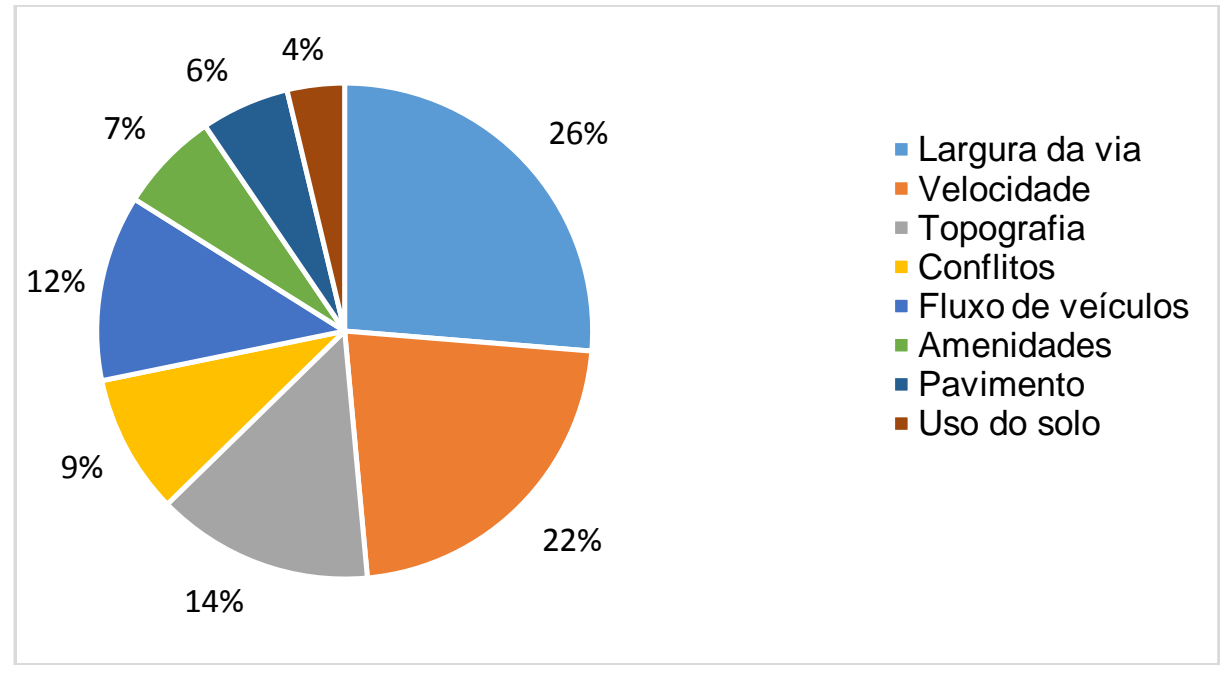

Fonte: Autor (2017).

Tabela 2: Indicadores e respectivos critérios e pesos que constituem o Índice de Condição da Via (ICV) para avaliação das rotas cicloviárias conforme Dixon (1996).

\begin{tabular}{|c|c|c|c|}
\hline Indicadores & Critérios & Referências & Peso \\
\hline \multirow{3}{*}{ Largura efetiva mínima: $(0,26)$} & Vias compartilhadas & $\begin{array}{l}<4,20 \\
\geq 4,20\end{array}$ & $\begin{array}{l}0 \\
0,26\end{array}$ \\
\hline & Ciclofaixas & $\begin{array}{l}<4,80 \\
\geq 4,80\end{array}$ & $\begin{array}{l}0 \\
0,26\end{array}$ \\
\hline & Ciclovias & $\begin{array}{l}<5,00 \\
\geq 5,00\end{array}$ & $\begin{array}{l}0 \\
0,26\end{array}$ \\
\hline \multirow{2}{*}{$\begin{array}{l}\text { Diferencial de velocidade entre } \\
\text { veículos e bicicleta: }(0,22)\end{array}$} & \multicolumn{2}{|l|}{$\begin{array}{l}>48 \mathrm{~km} / \mathrm{h} \\
32 \text { a } 48 \mathrm{Km} / \mathrm{h}\end{array}$} & $\begin{array}{l}0 \\
0.11\end{array}$ \\
\hline & \multicolumn{2}{|c|}{24 a 32 Km/h (Dixon, 1996) } & 0,22 \\
\hline \multirow{3}{*}{ Conflitos: $(0,09)$} & \multicolumn{2}{|c|}{ Ausência de estacionamento nas laterais } & 0,03 \\
\hline & \multirow{2}{*}{\multicolumn{2}{|c|}{$\begin{array}{l}\text { Ausências de entradas de garagens e cruzamentos } \\
\text { Ausências de barreiras }\end{array}$}} & 0,03 \\
\hline & & & 0,03 \\
\hline \multirow{3}{*}{ Manutenção das vias: $(0,06)$} & \multirow{3}{*}{\multicolumn{2}{|c|}{$\begin{array}{l}\text { Problemas graves ou frequentes } \\
\text { Problemas pequenos ou ocasionais } \\
\text { Sem problemas }\end{array}$}} & 0 \\
\hline & & & 0,03 \\
\hline & & & 0,06 \\
\hline \multirow{3}{*}{ Fluxo de Veículos: $(0,12)$} & \multirow{3}{*}{\multicolumn{2}{|c|}{$\begin{array}{l}\text { Alto fluxo - mais de } 3 \text { faixas rolamento } \\
\text { Médio Fluxo - entre } 2 \text { e } 3 \text { faixas rolamento } \\
\text { Baixo fluxo - uma faixa rolamento }\end{array}$}} & 0 \\
\hline & & & 0,06 \\
\hline & & & 0,12 \\
\hline \multirow{2}{*}{ Amenidades: $(0,07)$} & \multirow{2}{*}{\multicolumn{2}{|c|}{$\begin{array}{l}\text { lluminação } \\
\text { Arborização - sombra durante parte do dia }\end{array}$}} & 0,035 \\
\hline & & & 0.035 \\
\hline \multirow{3}{*}{ Topografia (Aclive): $(0,14)$} & \multirow{3}{*}{\multicolumn{2}{|c|}{$\begin{array}{l}\text { Indesejável } \\
\text { Aceitável } \\
\text { Desejável }\end{array}$}} & 0 \\
\hline & & & 0.07 \\
\hline & & & 0.14 \\
\hline Sinalização: $(0,04)$ & \multicolumn{2}{|c|}{$\begin{array}{l}\text { Inexistente } \\
\text { Existente (vertical e/ou horizontal) }\end{array}$} & 0 \\
\hline
\end{tabular}


Valor total

O índice do trecho = soma dos pontos nas oito categorias

Peso do trecho $=$ comprimento do trecho/comprimento da rota

Índice ajustado do trecho = índice do trecho x peso do trecho

Índice da rota = soma dos índices ajustados dos trechos que constitui cada rota

Para a avaliação dos trechos é necessário verificar qual tipo de ciclovia é indicado, tendo como premissa a hierarquia viária e funcional das vias estabelecida no Código Brasileiro de Trânsito (1997) e Caderno de Referência para a Elaboração de Plano de Mobilidade por Bicicleta nas Cidades do Ministério das Cidades (2007). A dimensão dos eixos viários foi obtida por meio de medições no local, enquanto a topografia foi obtida elaborando mapa temático da área por meio do SIG. Os dados fazem parte do Mapa Urbano Básico Digital de Goiânia - MUBDG, versão 23 de 2011 (ver Figura 7).

Figura 7: Curvas de nível da área estudada.

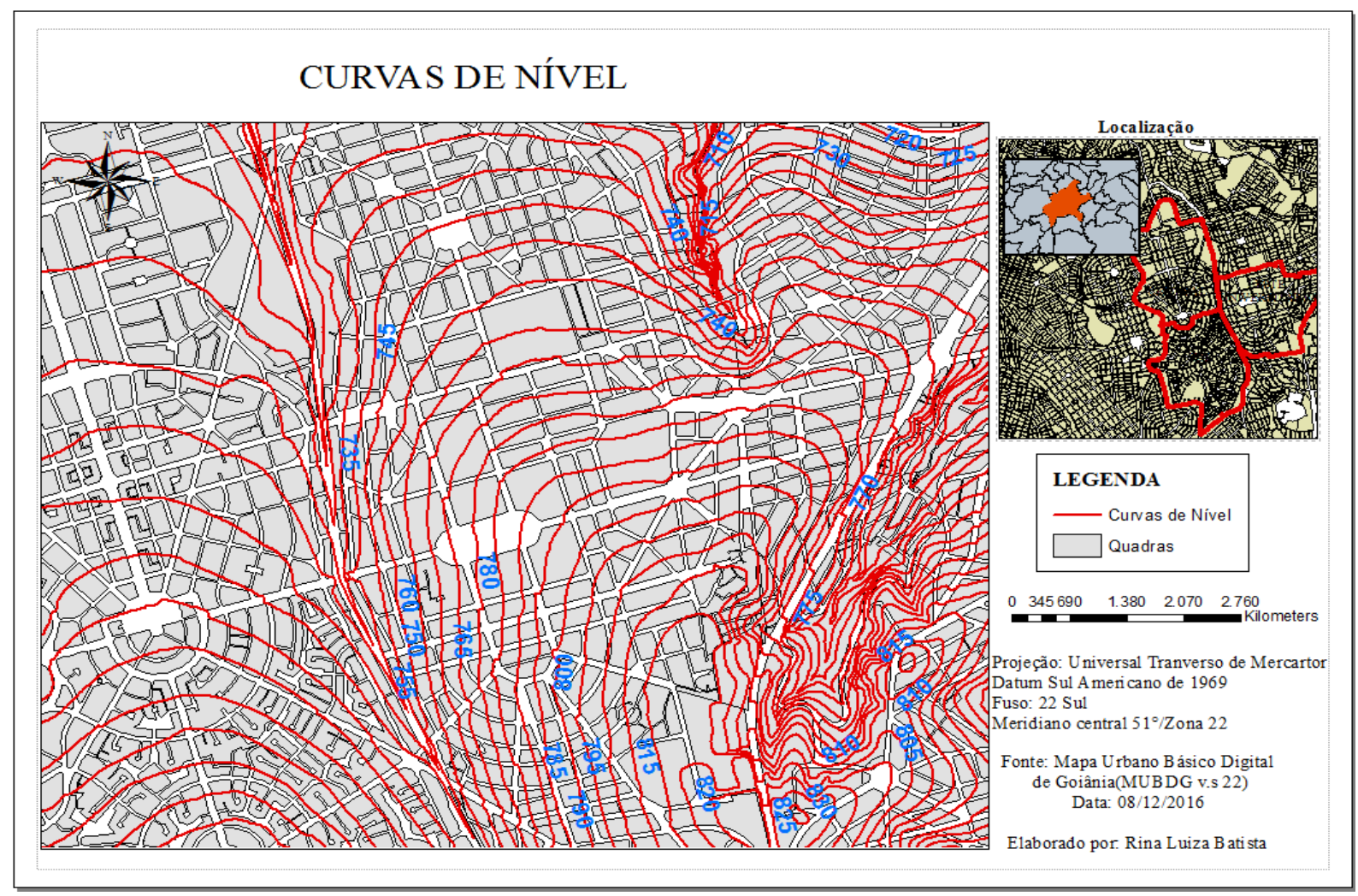

Fonte: MUBDG (2016)

Avaliaram-se os oito indicadores que constituem o Índice de Condição da Via (tabela 2) para determinar o valor do ICV de cada trecho. O resultado é sintetizado na tabela 3.

Tabela 3: Extensão e Índice de Condição da Vida (ICV) de cada trecho analisado.

\begin{tabular}{lrc}
\hline Trecho & Extensão $(\mathbf{m})$ & ICV \\
\hline Trecho 1 & 600 & 0,80 \\
Trecho 2 & 450 & 0,66 \\
Trecho 3 & 600 & 0,83 \\
Trecho 4 & 450 & 0,80
\end{tabular}




\begin{tabular}{crc} 
Trecho 5 & 700 & 0,94 \\
Trecho 6 & 350 & 0,84 \\
Trecho 7 & 1.000 & 0,74 \\
Trecho 8 & 450 & 0,80 \\
\hline
\end{tabular}

Usando os dados apresentados na tabela 3 para a avaliação final do ICV foi possível calcular o peso de cada trecho, a saber: peso do trecho = comprimento do trecho/comprimento da rota; índice ajustado do trecho = índice do trecho $\mathrm{x}$ peso do trecho; e índice da rota = soma dos índices ajustados dos trechos que constitui cada rota (ver tabela 4).

Tabela 4: Classificação dos trechos para diferentes rotas usando os ICV's.

\begin{tabular}{|c|c|c|c|c|c|c|}
\hline \multirow[t]{2}{*}{ Trecho } & \multirow[t]{2}{*}{ ICV } & \multicolumn{2}{|c|}{ Peso do Trecho } & \multicolumn{2}{|c|}{ Índice Ajustado } & \multirow[t]{2}{*}{ Classificação } \\
\hline & & Rota 1 & Rota 2 & Rota 1 & Rota 2 & \\
\hline T $1-600 \mathrm{~m}$ & 0,80 & 0,21 & 0,19 & 0,16 & 0,15 & A \\
\hline T $2-450 \mathrm{~m}$ & 0,66 & 0,16 & & 0,10 & & B \\
\hline T $3-600 \mathrm{~m}$ & 0,83 & 0,21 & & 0,17 & & A \\
\hline T $4-450 \mathrm{~m}$ & 0,80 & 0,16 & & 0,12 & & A \\
\hline T $5-700 \mathrm{~m}$ & 0,94 & 0,26 & 0,22 & 0,24 & 0,05 & A \\
\hline T $6-350 \mathrm{~m}$ & 0,84 & & 0,12 & & 0,10 & A \\
\hline T $7-1000 \mathrm{~m}$ & 0,74 & & 0,32 & & 0,23 & A \\
\hline T $8-450 \mathrm{~m}$ & 0,80 & & 0,15 & & 0,12 & A \\
\hline Ind. das Rotas IR & & & & 0,82 & 0,65 & \\
\hline
\end{tabular}

Como complemento a análise, propôs—se aplicar um processo de normatização análogo ao proposto por Eastman e Jiang (1996) em que são classificados os trechos em A, B ou C. Nesta escala se o valor do índice para o trecho estiver entre 0 e 0,33 é considerado ruim (C). De 0,33 até 0,67, o trecho apresenta uma boa situação (B). Quando o resultado apresentar valor superior a 0,68 , tem-se uma situação ótima (A) (ver tabela 4). Assim, é possível identificar a rota com maior necessidade de melhoramentos.

\subsection{Etapa 5: Avaliação das Oportunidades de Intervenção}

Esta etapa consiste de avaliação das rotas cicloviárias, onde agregaram-se as informações levantadas e estudadas de forma a valorizar os princípios norteadores de implantação de ciclovias apresentados pelo Ministério das Cidades (2007) e Kirner (2006) como referencial, na definição de rotas eficientes, a saber: rotas diretas/rapidez, coerência/atratividade, segurança viária, implementação de proposta.

\subsubsection{Avaliação das rotas diretas/rapidez}

A rota 1 possui melhor desempenho por ter menor extensão entre os PGV's com dimensão de 2.800 $\mathrm{km}$, sendo que a Rota 2 possui $3.100 \mathrm{~km}$. 


\subsubsection{Avaliação da coerência/atratividade}

A rota 1, por ser parte integrante do corredor exclusivo do transporte coletivo, existe maior demanda de circulação viária, o fluxo de pedestres é mais intenso por estar mais próxima das universidades, nos trechos 2, 3 e 4 existe número maior de comércio no local, favorecendo a atratividade da região, dinamizando a relação entre as pessoas, mercadorias, matérias e energia, no local, o que traz maior segurança ao local. A rota 2, no período noturno, principalmente, apresenta fluxo de pessoas e veículos menos intenso, comparado à rota 1 .

\subsubsection{Avaliação da segurança viária}

As duas rotas podem ser consideradas seguras para ciclistas, as larguras encontradas nos eixos viários permitem a implantação do sistema viário de forma a não caracterizar situações de estresse, assim como seu baixo número de intersecções sem sinalização. Na rota 1 a presença do ônibus poderia ser um elemento intimidador no deslocamento por bicicleta, mas há espaço físico para implantação de ciclovias, tornando-o favorável. Vale ressaltar que no Corredor Universitário há câmeras para monitoramento da segurança do local, trazendo "sensação de segurança" ao usuário.

\subsubsection{Avaliação da implementação de propostas}

A rota 1 apresenta o trecho 2 com índice pouco satisfatório, o indicador de topografia - aclive de 5,3\% com $450 \mathrm{~m}$, o que comprometeu o ICV do trecho $(0,66)$. Assim, buscou-se substituir o trecho para minimizar o efeito da aclividade. Os demais índices dos trechos analisados tiveram ICV classificados como "ótima" não necessitando de mais intervenções. Há de se pontuar que a avaliação realizada foi feita após a intervenção e implantação da ciclovia, juntamente com o corredor exclusivo e calçada. A rota 2 apresenta o trecho 6 com sentido único, permissão de estacionamentos de carros nas duas laterais da via, o que possibilita a inclusão de ciclofaixas sem interferência no número de faixas.

\subsection{Etapa 6: Seleção da Rota de Melhor Desempenho}

Após a análise das possíveis intervenções e com os dados avaliativos de cada trecho foi possível comparar os trechos a fim de escolher a rota de melhor desempenho. A tabela 5 apresenta a comparação das rotas considerando o ICV e os outros quatro critérios norteadores de implantação de ciclovias apresentados pelo Ministério das Cidades (2007) e Kirner (2006). Assim, o estudo de caso comprovou a aplicabilidade do método proposto, indicando a Rota 1 como sendo a mais favorável para a implantação de rota cicloviária dentro da área de estudo.

Tabela 5: Comparativo entre as rotas analisadas.

\begin{tabular}{|c|c|c|}
\hline Critérios Analisados & Rota 1 & Rota 2 \\
\hline Indice das Rotas (ICV) & 0,8 & 0,65 \\
\hline Rotas diretas/rapidez & & \\
\hline Coerência/atratividade & & \\
\hline Segurança viária & & \\
\hline Implementação de melhorias & & \\
\hline
\end{tabular}




\section{Conclusão}

A política de mobilidade urbana em vigência na maioria das cidades brasileiras foi orientada pelo e para o transporte motorizado individual, modelo este que traz sinais de esgotamento em face aos constantes congestionamentos e problemas que se apresentam em nossas cidades. Os problemas urbanos causados pelo planejamento de transporte que prioriza o uso do automóvel em detrimento de outros meios de transporte indicam a bicicleta como uma alternativa viável e sustentável de transporte urbano nas cidades brasileiras. No entanto, boa parte da frota brasileira de bicicletas não circula, principalmente pela falta de segurança do ciclista no trânsito das cidades, e pela falta de políticas de integração para esse tipo de transporte.

Neste sentido, este trabalho contribuiu com um procedimento metodológico que colabora para o planejamento e avaliação de rotas cicloviárias, visando ações efetivas de fomento ao uso da bicicleta, sem que sejam onerosas ao poder público e que sejam atrativas aos usuários, integrando os requisitos técnicos da implantação de rotas cicloviárias, com características comportamentais que interferem na decisão por parte do usuário em se utilizar a bicicleta, apresentadas pela Psicologia Ambiental, tais como: territorialidade, privacidade, densidade e apinhamento. Tais características foram representados pelos seguintes indicadores na concepção do ICV: i) largura da via; ii) velocidade; iii) conflitos; e iv) amenidades. Assim buscou-se apresentar um método de fácil aplicação, por englobar indicadores que auxiliam no processo de decisão, além de apresentar o índice que facilita a identificação de uma rota ou trecho mais eficiente, a fim de facilitar a implementação de infraestruturas cicloviárias.

Ressalta-se que a escolha dos indicadores foi baseada nos parâmetros e critérios dos métodos de avaliação dos níveis de serviço de ciclovias (foco comportamental), assim como na relação que se estabelece nos critérios da Psicologia Ambiental focados por Hamer e Almeida (2016b), em que prevaleceram oito indicadores que se integram ao quadro de análise do Índice de Condição da Via ICV.

Quanto aos critérios avaliados, contatou-se que a largura da via é o fator mais relevante, entre os entrevistados $(26 \%)$, considerando que a infraestrutura cicloviária deve ser implantada em vias com tráfego motorizados e de pedestres já consolidados. A avaliação da largura da via e o espaço disponível para a implantação da rota cicloviária com segurança são o principal problema enfrentado pelas grandes cidades, já que os congestionamentos de carros são derivados da falta de espaço viário.

O critério de velocidade das vias atingiu o valor secundário de importância com $22 \%$ entre os entrevistados. O Código de Trânsito Brasileiro (BRASIL, 1997) estabelece velocidades máximas para cada tipo de via e estas já possuem volume de veículos a ela associado, assim a hierarquia viária foi indicada como um requisito na escolha do sistema viário a ser implantado. Sugere-se como futuro trabalho a ser desenvolvido sobre o tema a aplicação da metodologia considerando amostra maior e outros pares $\mathrm{O} / \mathrm{D}$ de uma rede cicloviária.

\section{Referências}

ALTMAN, I. Environment and Social Behaviour: Privacity, personal space, territory and crowding. Monterre, CA: Brooks/Cole, 1975.

ANTP - Associação Nacional de Transporte Públicos. Transporte Humano. Cidades com qualidade de Vida. São Paulo, SP. Disponível em: http://www.antp.org.br. Acesso: 04 maio de 2017, 2004.

ANTP - Associação Nacional de Transporte Público. Sistema de Informações de Mobilidade, Relatório Geral de 2016. Publicado em mai. 2018. Disponível: http://files.antp.org.br/simob/simob-2016-v6.pdf . Acesso em: 03 janeiro de 2020, 2018. 
BATISTA, J. A. Reflexões sobre o Conceito Antropológico de Cultura. Revista Saber Eletrônico. Ano 1 Vol Nov $\quad$ - $\quad$ Jun. 2010.2 Disponível em: http://www.unifaj.edu.br/NetManager/documentos/reflexoes\%20sobre\%200\%20conceito\%20antropolog ico\%20de\%20cultura.pdf. Acesso em: 26 junho de 2017, 2010.

BELL, P. A.; GREENE, T. C.; FISHER, J. D.; BAUM, A. Environmental Psychology (5th ed.). Belmont, CA: Wadsworth/Thomson, 1996.

BRASIL. Lei n. 9.503, 23 de setembro de 1997. CTB - Código de Trânsito Brasileiro. Diário Oficial da União, Brasília, DF. Disponível em: http://www.planalto.gov.br/ccivil_03/leis/L9503.htm. Acesso: 08 de junho de 2017, 1997.

Secretaria Nacional de Transportes e da Mobilidade Urbana. Caderno de Referência para a Elaboração de Plano de Mobilidade por Bicicleta nas Cidades - Semob, Brasília, DF, 2007.

. Lei n 12.587, de 3 de janeiro de 2012. Lei Federal de Mobilidade Urbana. Diário Oficial da União, Brasilia, DF. Disponível em: http://www.planalto.gov.br/ccivil_03/_ato20112014/2012/lei//12587.htm. Acesso: 26 julho de 2016, 2012.

DAVIS, G.; Wicklatz, T. Sample Based Estimation of Bicycle Miles of Travel (BMT). Published Report. Minnesota Department of Transportation, St Paul, MN, 2001.

Delabrida, Z. N. C. A imagem do Uso da Bicicleta: Um estudo entre moradores de Taguatinga. Dissertação de Mestrado. Universidade de Brasília, Brasília, DF, 2004.

Eastman J. R.; Jiang, H. Fuzzy Measures in Multi-criteria Evaluation. In: Proceedings, Second International Symposium on Spatial accuracy Assessments in Natural resources Environmental Studies".Fort Collins, Colorado. p.527-534,1996.

EVERETT, P. B.; WATSON, B. G. Psychological Contributions to Transportation. Em D. Stokols \& I. Altman (Eds.), Handbook of environmental psychology, vol II (pp. 987-1008). New York: Wiley, 1987.

FHWA - Federal Highway Administration. Guide on Methods to Estimate Non - Motorized Demand Travel. Supporting Documentation. Washington USA D.C, 1999.

GEHL, J. Cidade para Pessoas. Editora Perspectiva, 3a Edição Di Marco, São Paulo, SP, 2015.

GEIPOT - Grupo Executivo de Integração da Política de Transporte. Planejamento Cicloviário: Diagnóstico Nacional. Brasília, DF. Disponível em: https://drive.google.com/file/d/OBxR5Ri6g5X_ZTXVWS3pyVUdPdDA/view. Acesso: 03 maio de 2015, 2001.

Gifford, R. Environmental Psychology: Principles and Practical (2ª ed.) Boston: Allyn e Bacon, 1997.

GOIÂNIA. Lei Complementar n.169, de 15 de fevereiro de 2007. Dispõe sobre o uso da bicicleta e o sistema cicloviário e dá outras providências. Diário Oficial do Município de Goiânia, GO, 2007.

GUNTHER, H. Mobilidade e "affordance" como cerne dos Estudos Pessoa-Ambiente. Estudos de Psicologia, 8(2).273-280. UnB . Brasília, DF, 2003.

HALL. E. T. The hidden dimension, New York, Doubleday, 1966. Disponível em: www.philoonline.com/TEXTES/HALL Edward Twichell - The hidden dimension.pdf. Acesso em: 10 jan. 2017, 1966.

HAMER, L. J.; ALMEIDA C. F.; ANDRADE, K. Contribuição para definição de diretrizes para Implantação de ciclovias com base na identificação do perfil do Usuário potencial de bicicletas: Um estudo no 
Corredor Universitário de Goiânia. XXIX ANPET. Ouro Preto, MG, 2016a.

HAMER, L. J.; ALMEIDA C. F. Variáveis Psicológicas e o Nível de Serviço que Predizem a Mobilidade Urbana na Implantação de Ciclovias. VII Congresso Luso Brasileiro para o Planejamento Urbano, Regional, Integrado e Sustentável PLURIS 2016. Maceió, AL, 2016b.

HEIMSTRA, N.W.; McFARLING L. H. Psicologia Ambiental. Tradução de Manoel Andrade Schmidt, São Paulo: EPU: Ed. da Universidade de São Paulo, SP, 1978.

IBGE - Instituto Brasileiro de Geografia e Estatísticas. Censo de 2010, 2010. Disponível em: http://www.ibge.gov.br, Acesso em: 15 novembro de 2010.

ITDP Brasil. Guia de Planejamento Cicloinclusivo. Disponível em: http://itdpbrasil.org/guiacicloinclusivo/. Acesso em: 05 janeiro de 2020, 2017.

KIRNER, J. Proposta de um Método para a Definição de Rotas Cicláveis em Areas Urbanas, Dissertação (Mestrado) - Universidade Federal de São Carlos, São Carlos, SP, Brasil. 110f, 2006.

KNEIB, E. C. Caracterização de Empreendimentos Geradores de Viagens: Contribuição Conceitual à Análise de seus Impactos no Uso, Ocupação e Valorização do Solo Urbano. Dissertação de mestrado em Transportes, UnB. Brasília, DF, 2004.

LEE, T. Psicologia e meio ambiente. Rio de Janeiro: Zahar. 1977.

LEWIN, K. Forças Ambientais no Comportamento e Desenvolvimento Infantil. In K.Lewin, Teoria dinâmica da personalidade (pp.71-115) Ed. Cutrix São Paulo, SP, 1975.

MAOSKI, F. Ter carro é... A percepção sobre o significado do carro e o comportamento do condutor. Dissertação da Universidade Federal do Paraná Setor de Ciências Humanas Letras e Artes Programa de Pós-Graduação Mestrado em Psicologia, Curitiba, PR, 2014.

MATOS, M. A. Controle de estímulos condicional, formação de classes soceituais e comportamentais cognitivas. Revista Brasileira de Terapia Comportamental Cognitiva, 1(2) 159-178, São Paulo, 1999.

MINISTÉRIO DAS CIDADES. Secretaria Nacional de Transportes e da Mobilidade Urbana. Caderno de Referência para a Elaboração de Plano de Mobilidade por Bicicleta nas Cidades - Ministério das Cidades, Semob, Brasília, DF, 2007.

MORVAL, J. Psicologia Ambiental. Coleção Epigénese, desenvolvimento e psicologia; Tradução de António Viegas. Instituto Piaget. Lisboa, Portugal, 2007.

MOSER, G. Psicologia Ambiental. Estudos de Psicologia, 3(1), 121-130, 1998.

MOYSÉS, A. Novas tendências do Empreendedorismo imobiliário na metrópole goianiense: a produção imobiliária de alto nível. 1ํ Simpósio Nacional de Empreendedorismo Social Enactus Brasil. Fortaleza, CE. Disponível em: http://sites.google.com/a/metrowiki.net/observat-rio-das-metr-poles-workshopfortaleza.Acesso em 27/05/2017, 2008.

PAIVA, M. Fatores que Influenciam no Uso da Bicicleta de Forma Integrada com o Metrô. Tese de doutorado em Transportes, Publicação T. D - 002A/2013, Departamento de Engenharia Civil e Ambiental, UnB, Brasília, DF, 206 p., 2013.

PEZZUTO, C. C. Fatores que influenciam o uso da bicicleta. Dissertação de Mestrado em Engenharia Urbana - centro de Ciências Exatas, Universidade São Carlos , São Carlos, SP, 2002.

PORTUGAL, L. S.; GOLDNER, L. G. Estudo de Pólos Geradores de Tráfego e de seus Impactos nos 
Sistemas Viários e de Transportes. Editora Edgard Blucher, Rio de Janeiro, RJ, 2003.

PUCHER, J.; BUEHLER R. Cycling for Everyone: Lessons from Europe. Rutgers University. New Jersey. Disponível em: http://policy.rutgers.edu/faculty/pucher/Cycling\%20for\%20Everyone\%20TRB.pdf. Acesso: 07 abril 2017, 1999.

RAMOS, P. A. M. Projecto de Ciclovias. Dissertação de Mestrado, Escola de Engenharia Civil Departamento de Transportes, Universidade de Porto. Lisboa, Portugal, 2008.

RIETVEL P.; DANIEL, V. Determinants of Bicycle Use: Do Municipal Policies Matter? Transportation Research Part A-Policy and Practice, 7, 531-550. Disponível em: http://www.scirp.org/reference/ReferencesPapers.aspx?ReferencelD=1646743 Acesso em 14 abril 2017, 2004.

SAATY, T. L. The Analytic Hierarchy Process. Tradução e revisão por Wainer da Silveira e Silva, McGraw-Hill, Makron, São Paulo, SP, Brasil, pp. 278, 1991.

SEGADILHA, A. B. P. Identificação dos fatores que Influenciam na escolha da rota pelos ciclistas : Estudo na cidade de São Carlos . Dissertação do Programa de Pós Graduação em Engenharia Urbana, Universidade Federal de São Carlos. São Carlos, SP, 2014.

SEPLAM, Secretaria Municipal de Planejamento e Urbanismo Municipal. DPESE - Departamento de Pesquisa e Estatística e Estudos Sócio Econômico, 2010. Disponível em; http://www.goiania.go.gov.br/shtml/seplam/anuario2012/arquivos\%20anuario/3\%20DEMOGRAFIA/3.5 \%20Popula\%C3\%A7\%C3\%A30\%20por\%20Bairros/3.5.1\%20\%20Estimativa\%20\%20Redistribui\%C3\%A7\%C3\%A30\%20da\%20popula\%C3\%A7\%C3\%A30\%20resid ente\%20em\%20Goi\%C3\%A2nia,\%20por\%20bairro\%20e\%20g\%C3\%AAnero\%20-\%202010.pdf

SOMMER, R. Personal Space. Englewood Cliffs: Prentice-Hall, 1969.

STOKOLS, D. Bridging the theoretical and applied facets of Environmental Psychology. American Psychologist, Ed.51a, 1188- 1189, 1996.

TUAN, Yi-F. Espaço e lugar: a perspectiva da experiência. São Paulo: Difel, 1983.

TYLOR, E.B. Primite Culture - Research into the development of mythology, philosophy, religion language, art and custom. University of Toronto, Vol. 01, 6 ${ }^{\underline{a}}$ Edition, 1871.Disponível em https://archive.org/stream/primitiveculture01 tylouoft\#page/n17/mode/2up. Acesso dia 10/04/2017, 1871.

VASCONCELLOS, E. A. Transporte Urbano nos Países em Desenvolvimento: reflexões e propostas, 3a edição Editora Annablume, São Paulo, SP, 2000.

VILLAÇA, L. B. Comportamento sócio-espacial de pessoas em movimento: um estudo exploratório no calçadão da Avenida Engenheiro Roberto Freire. Dissertação de Mestrado - Programa de Pósgraduação em Psicologia. Universidade Federal do Rio Grande do Norte, Natal, RN, 2008. 


\section{Cristiano Farias Almeida}

Possui graduação em Engenharia Civil pela Universidade Federal do Pará (1999), mestrado em Transportes pela Universidade de Brasília (2001), doutorado em Transportes pelo Nagoya Institute of Technology no Japão e pela Universidade de Brasília (2008), e Pós-Doutorado em Desenvolvimento de Cluster Logístico pela Université de Liège na Bélgica (2020). Atualmente é Professor Associado, Classe D, Nível 2 da Universidade Federal de Goiás. É professor permanente do Programa de PósGraduação Projeto e Cidade (PPGPC). Atualmente desempenha a função de coordenador do curso de Engenharia de Transportes. É atualmente Embaixador do Wallonie-Bruxelles Internacional.be (WBI) no Brasil. Elaborou o projeto de implantação do primeiro curso de Engenharia de Transportes Bacharelado da Universidade Federal de Goiás, do qual desempenhou função de Coordenador entre 2015 e 2018. Foi membro da Comissão de Implantação da Faculdade de Ciências e Tecnologia (FCT) da UFG.

Contribuição de coautoria: Concepção; Análise; Supervisão; Validação; Redação - rascunho original, Redação - revisão e edição.

\section{Luciana Joyce Hamer}

Graduada em Arquitetura e Urbanismo pela Pontifícia Universidade Católica de Goiás, Brasil. Especialização em Engenharia de Segurança do Trabalho pela Pontifícia Universidade Católica de Goiás. Mestre em Mobilidade Urbana pelo Programa de Pós-Graduação em Projeto e Cidades da Universidade Federal de Goiás.

Contribuição de coautoria:Curadoria de dados; Análise, Coleta de dados; Metodologia; Redação revisão.

\section{Mario Cools}

PhD em Ciências de Transporte pela Universidade de Hasselt, Bélgica. Mestre em Estatística Aplicada pela Universidade de Hasselt, Bélgica. Mestre em Ciências Econômicas pela Universidade da Antuérpia, Bélgica. Atualmente é professor assistente Universidade de Liège; Centro de Transporte, Mobilidade e Logística; Departamento de Engenharia Urbana e Ambiental. Membro da "Society for Multivariate Analysis in the Behavioural Sciences (SMABS)", membro da "European Survey Research Association (ESRA)". Possui dezenas de artigos científicos publicados em periódicos especializados. Desenvolve inúmeros projetos de pesquisa fomentados pelo governo belga. Orientou dezenas de dissertações de mestrado e teses de doutorado dentro da área de transportes.

Contribuição de autoria: Supervisão; Validação; Visualização; Redação - revisão e edição.

Como citar: Almeida, C. F., Hamer, L. J. ., \& Cools, M. . (2021). Metodologia para Avaliação de Rotas Cicloviárias sob o Enfoque da Psicologia Ambiental. Paranoá: Cadernos De Arquitetura E Urbanismo, (31). https://doi.org/10.18830/issn.1679-0944.n31.2021.04

Editora responsável: Maria do Carmo de Lima Bezerra 